Analytical Methods

\title{
Determination of paraquat and diquat: LC-MS method optimization and validation
}

\author{
Ionara R. Pizzutti ${ }^{\mathrm{a}, *}$, Giovana M.E. Vela ${ }^{\mathrm{a}}$, André de Kok ${ }^{\mathrm{b}}$, Jos M. Scholten ${ }^{\mathrm{b}}$, Jonatan V. Dias ${ }^{\mathrm{a}}$, \\ Carmem D. Cardoso ${ }^{\mathrm{a}}$, Germani Concenço ${ }^{\mathrm{c}}$, Rafael Vivian ${ }^{\mathrm{d}}$ \\ ${ }^{a}$ Federal University of Santa Maria, Chemistry Department, Center of Research and Analysis of Residues and Contaminants (CEPARC), Santa Maria, RS, Brazil \\ ${ }^{\mathrm{b}}$ NVWA - Netherlands Food and Consumer Product Safety Authority, Laboratory of Food and Feed Safety, Chemistry Laboratory, RED Group, \\ National Reference Laboratory (NRL) for Pesticide Residues in Food and Feed, Wageningen, The Netherlands \\ ${ }^{\mathrm{c}}$ Brazilian Agricultural Research Corporation (EMBRAPA) - Western Region Agriculture, Dourados, MS, Brazil \\ ${ }^{\mathrm{d}}$ Brazilian Agricultural Research Corporation (EMBRAPA) - Products and Markets, Brasilia, DF, Brazil
}

\section{A R T I C L E I N F O}

\section{Article history:}

Received 27 May 2015

Received in revised form 2 December 2015

Accepted 18 April 2016

Available online 19 April 2016

\section{Keywords:}

Cowpea

Bipyridylium herbicides

Paraquat

Diquat

UPLC-MS/MS

\begin{abstract}
A B S T R A C T
This study describes the optimization and single-laboratory validation of a single residue method for determination of two bipyridylium herbicides, paraquat and diquat, in cowpeas by UPLC-MS/MS in a total run time of $9.3 \mathrm{~min}$. The method is based on extraction with an acidified methanol-water mixture. Different extraction parameters (extraction solvent composition, temperature, sample extract filtration, and pre-treatment of the laboratory sample) were evaluated in order to optimize the extraction method efficiency. Isotopically labeled internal standards, Paraquat-D6 and Diquat-D4, were used and added to the test portions prior to extraction.

The method validation was performed by analyzing spiked samples at three concentrations (10, 20 and $\left.50 \mu \mathrm{g} \mathrm{kg}^{-1}\right)$, with seven replicates $(\mathrm{n}=7)$ for each concentration. Linearity $\left(\mathrm{r}^{2}\right)$ of analytical curves, accuracy (trueness as recovery \% and precision as RSD\%), instrument and method limits of detection and quantification (LOD and LOQ) and matrix effects were determined. Average recoveries obtained for diquat were between 77 and $85 \%$ with RSD values $\leqslant 20 \%$, for all spike levels studied. On the other hand, paraquat showed average recoveries between 68 and 103\% with RSDs in the range $14.4-25.4 \%$. The method LOQ was 10 and $20 \mu \mathrm{g} \mathrm{kg}^{-1}$ for diquat and paraquat, respectively. The matrix effect was significant for both pesticides. Consequently, matrix-matched calibration standards and using isotopically labeled (IL) analogues as internal standards for the target analytes are required for application in routine analysis.

The validated method was successfully applied for cowpea samples obtained from various field studies.
\end{abstract} (C) 2016 Elsevier Ltd. All rights reserved.

\section{Introduction}

Paraquat (1,1'-dimethyl-4,4'-bipyridinium dichloride) and diquat (1,1'-ethylene-2,2'-bipyridyldiylium dibromide) are bipyridylium herbicides widely used in the world (Paraquat Information Center, 2015; The Pesticide Manual, 2012). Both are very polar substances, having a high solubility in water, $620 \mathrm{~g} \mathrm{~L}$ and $700 \mathrm{~g} \mathrm{~L}$, for paraquat and diquat, respectively (Paraquat Information Center, 2015).

Paraquat is a banned substance in the European Union (Maya, Estela, \& Cerdà, 2011; Yao et al., 2013), however, it is still applied in nearly 90 countries, such as China, Thailand and Brazil (ANVISA (Brazilian Sanitary Surveillance Agency), 2015; Paraquat

\footnotetext{
* Corresponding author.

E-mail address: ionara.pizzutti@ceparc.com.br (I.R. Pizzutti).
}

Information Center, 2015; Yao et al., 2013), which can cause problems through importation/exportation procedures over the whole world. It is used either to prepare the land for planting or for controlling weeds in more than 100 crops, including major crops as corn, rice, soya, wheat, potatoes, apples, oranges, bananas, coffee, tea, cocoa, cotton, palm oil and sugarcane (Paraquat Information Center, 2015).

Diquat is a non-selective herbicide, contact desiccant and it is also used for weed control. Among many other crops, it is recommended to be used on potato, coffee, beans, soya and citrus fruits (The Pesticide Manual, 2012).

The group of quaternary ammonium salts, also known as "quats", is a particular difficult type of herbicides (Shawish, Ghalwa, Hamada, \& Basheer, 2012) due their physico-chemical properties, which preclude their determination via multi-residue methods. Several analytical methods and techniques have been 
reported for paraquat and/or diquat determination. During the last few years, many voltammetric methods were described (Farahi, Achak, Gaini, Mhammedi, \& Bakasse, 2014; Harmoudi et al., 2012, 2013; Tyszczuk-Rotko, Beczkowska, \& Nosal-Wiercinska, 2014), as well as spectrophotometric (Maya et al., 2011), potentiometric (Shawish et al., 2012), spectrofluorimetric (Yao et al., 2013) and immunoassay methods (Garcia-Febrero, Salvador, SanchezBaeza, \& Marco, 2014). Some methods were developed using GC with solid-phase extraction (SPE) (Almeida \& Yonamine, 2007) and solid-phase microextraction (SPME) (Gao et al., 2014). Most of the cited studies were concerning environmental matrices, such as water (Maya et al., 2011; Shawish et al., 2012; Tyszczuk-Rotko et al., 2014; Yao et al., 2013) and biological matrices, such as urine and human plasma (Shawish et al., 2012; Almeida \& Yonamine, 2007; Gao et al., 2014). Nowadays, LC coupled with tandem mass spectrometry (LC-MS/MS) and ESI ionization, is becoming the most preferable approach, due to parameters as sensitivity and selectivity (Hao et al., 2013; Ruan et al., 2014).

However, often obtained inconsistent results for the paraquat determination suggested problems with the chromatographic and/or mass spectrometric behavior of mainly paraquat (Hao et al., 2013). Three types of quasi-molecular ions, radical cations $\mathrm{M}^{+} \cdot(\mathrm{m} / z 184$ for DQ and $m / z 186$ for PQ), singly charged cations $[\mathrm{M}+\mathrm{H}]^{+}(\mathrm{m} / z 183$ for $\mathrm{DQ}$ and $\mathrm{m} / z 185$ for $\mathrm{PQ})$ and dications $\mathrm{M}^{2+}$ ( $m / z 92$ for DQ and $m / z 93$ for PQ), were observed in the ESI mass spectra of DQ and PQ (Castro, Moyano, \& Galceran, 2001; Grey, Nguyen, \& Yang, 2002). Neither the MRM transitions nor the ESI capillary voltages described in the literature for the quantitation of DQ and PQ were consistent (Hao et al., 2013).

In 2012, Kolberg et al. (2012) developed and validated a method using isotope dilution mass spectrometry (IDMS) to compensate for paraquat and diquat losses during the whole analytical procedure in order to improve accuracy and precision. Then, based on the method (QuPPe-Method) of the European Union Reference Laboratory for Pesticides Requiring Single Residue Methods (EURL-SRM) (Anastassiades et al., 2013), our group started further optimizing the sample extraction parameters, such as extraction solvent composition, temperature, sample extract filtration and pre-treatment of the laboratory sample, also applying IDMS, in order to obtain acceptable results, mainly for paraquat. The optimized method was finally validated for cowpea beans, according to document No. SANCO/12571/2013 (SANCO, 2013). The method developed for this study was successfully applied for samples from an EMBRAPA field study.

\section{Experimental}

\subsection{Chemical and reagents}

Acetonitrile, pesticide grade (99.9\%) and formic acid, analytical grade (99.8\%), were purchased from J.T. Baker (Phillipsburg, NJ, USA); ammonium formate (99.0\%) from Fluka Analytical (Seelze, Germany). Methanol, pesticide grade (99.5\%), was obtained from Mallinckrodt (Phillipsburg, NJ, USA) and fuming hydrochloric acid ( $\mathrm{HCl}$, p.a., 37\%) from Casa da Química (Diadema, SP, Brazil). Reference standards of diquat dibromide (98\%), paraquat dichloride (97\%), diquat dibromide-D4 (98.5\%) and paraquat diiodide-D6 (98\%) were obtained from Dr. Ehrenstorfer (Augsburg, Germany).

\subsection{Standard solutions}

Standard stock solutions were prepared at $1 \mathrm{mg} \mathrm{mL}^{-1}$ in methanol, acidified with $1 \%$ formic acid. Paraquat diiodide-D6 was dissolved in water due to it's insolubility in organic solvents. Each compound was individually weighed directly into the $20 \mathrm{~mL}$ polypropylene tubes and immediately dissolved in the appropriate solvent. Finally, the solutions were placed for $5 \mathrm{~min}$ in an ultrasonic bath for complete dissolution.

From the individual stock solutions, a mixture of paraquat and diquat was prepared at $100 \mu \mathrm{g} \mathrm{mL}^{-1}$, which was further diluted with methanol to a concentration of $10 \mu \mathrm{g} \mathrm{mL}^{-1}$. For the preparation of analytical solutions, the $10 \mu \mathrm{g} \mathrm{mL}^{-1}$ mixture solution was diluted with methanol to concentrations of $0.1,1$ and $5 \mu \mathrm{g} \mathrm{mL}^{-1}$, which were then used for preparation of working standard solutions in solvent and in blank matrix extract.

Deuterated internal standards, paraquat-D6 and diquat-D4, were diluted with methanol from their individual stock solutions to a mixture with a concentration of $40 \mu \mathrm{g} \mathrm{mL}^{-1}$, which was used to spike samples for recovery studies and quantitation of the analytes in real samples. In order to use the deuterated standards in calibration standard solutions, at a fixed concentration, a solution was prepared at $2 \mu \mathrm{g} \mathrm{mL}^{-1}$ from the solution of $40 \mu \mathrm{g} \mathrm{mL} \mathrm{m}^{-1}$.

Analytical solutions were stored in a freezer at $-20^{\circ} \mathrm{C}$.

Before use, all solutions were taken out from the freezer and allowed to stand until room temperature was reached. Subsequently, the solutions were placed in an ultrasonic bath for $5 \mathrm{~min}$ to obtain complete dissolution.

\subsection{UPLC-MS/MS experimental conditions}

The chromatographic system consisted of an ACQUITY UPLC (ultra-performance liquid chromatograph) coupled to a XEVO TQS tandem mass spectrometer (Waters, Milford, MA, USA).

Chromatographic separations were carried out using a Sielc ${ }^{\circledR}$ Obelisc R column $(5 \mu \mathrm{m}, 2.1 \mathrm{~mm}$ i.d $\times 150 \mathrm{~mm})$, maintained at $40{ }^{\circ} \mathrm{C}$. The LC mobile phases consisted of water containing $20 \mathrm{mM}$ ammonium formate, acidified to $\mathrm{pH} 3$ with formic acid (solvent $\mathrm{A}$ ) and acetonitrile (solvent $\mathrm{B}$ ). The following gradient elution ( $0.4 \mathrm{~mL} \mathrm{~min}^{-1}$ flow rate) was performed: $20 \% \mathrm{~A}$ at the time of injection, increasing linearly to $80 \%$ A over $5.2 \mathrm{~min}$. This eluent composition was maintained for $2.6 \mathrm{~min}$ and then decreased linearly to $20 \% \mathrm{~A}$. This condition was maintained for $1.5 \mathrm{~min}$.

The mass spectrometer was operated in the positive electrospray ionization mode $\left(\mathrm{ESI}^{+}\right)$. Two MRM transitions per analyte were monitored in the multiple reaction monitoring (MRM) mode for diquat $(183.1 \rightarrow 157.0$ for quantification; $183.1 \rightarrow 168.0$ for confirmation) and paraquat $(186.1 \rightarrow 171.1$ for quantification; $186.1 \rightarrow 77.0$ for confirmation). For isotopic labeled internal standards, only one transition (quantification) was monitored: $192.1 \rightarrow 174.1$ for paraquat-D6 and $186.1 \rightarrow 158.0$ for diquat-D4

Preliminary tuning experiments were carried out via direct infusion of diluted standard solutions ( $200 \mathrm{ng} \mathrm{mL}^{-1}$ ) into the mass spectrometer, in order to establish the optimal detection conditions. This procedure was done for labeled and unlabeled standards. The infusion flow rate was set at $5 \mu \mathrm{L} \mathrm{min}{ }^{-1}$.

\subsection{Optimization of sample preparation}

Cowpea samples were milled and grinded until a fine powder. Then, in order to obtain a completely homogeneous sample, a slurry of cowpea and water was prepared. To this end, the ground cowpea was homogenized with water using an Ultra-Turrax for $5 \mathrm{~min}$.

To optimize the homogeneity of the slurry preparation, different ratios of matrix/water were tested: $1: 1,1: 1.5,1: 3$, and $1: 4$ (milled cowpea:water, w:w). Respectively, 5, 4, 2.5 and $2 \mathrm{~g}$ of ground cowpeas were weighed, with an analytical balance, in 4 different Teflon (PTFE) bottles. To each bottle, respectively, 5, 6, 7.5 and $8 \mathrm{~g}$ of water (ultrapure quality) was added, and the mixture was homogenized using an Ultra-Turrax for $5 \mathrm{~min}$. The 
homogeneity of the slurry was determined visually and the most suitable ratio of cowpea/water was determined.

For this study, blank samples of cowpea were provided by Embrapa.

\subsection{Optimization of extraction parameters}

All optimization experiments were performed in triplicate and the recoveries presented in the results and discussion paragraph are the average $(n=3)$.

\subsubsection{Extraction solvent composition}

Methanol/acidified water was used as extraction solvent and various ratios of methanol/0.5 $\mathrm{mol} \mathrm{L}^{-1} \mathrm{HCl}(1: 1,6: 4,7: 3,8: 2,9: 1)$ were tested. The mixtures were prepared in $500 \mathrm{~mL}$ volumetric flasks. The use of $\mathrm{HCl}$ solution $0.1 \mathrm{~mol} \mathrm{~L}^{-1}$ instead of $0.5 \mathrm{~mol} \mathrm{~L}^{-1}$ was also studied.

\subsubsection{Temperature}

The influence of temperature on the extraction was tested as follows. After the addition of the extraction solvent, the tube containing the matrix and extraction solvent was left at room temperature or directly transferred to a water bath which was kept at $80^{\circ} \mathrm{C}$ for $15 \mathrm{~min}$.

The influence of the temperature during centrifugation was compared by taking the sample extract tubes directly from the water bath (at $80^{\circ} \mathrm{C}$ ), without cooling down, or after prior cooling down to room temperature, before centrifugation.

\subsubsection{Filtration}

The effect on recoveries of omitting or using a filtration step $(0.45 \mu \mathrm{m})$ after centrifugation, before injecting the final extract into the UPLC-MS/MS system, was tested.

\subsubsection{Optimized extraction method}

The final optimized method is as follows. From a homogenized slurry (matrix/water ratio of 1/1.5), $12.5 \mathrm{~g}$ analytical test portion (corresponding to $5 \mathrm{~g}$ original cowpea) is taken and the isotopically labeled internal standards are added. This portion is transferred to a $50 \mathrm{~mL}$ polypropylene centrifuge tube. Then, $10 \mathrm{~mL}$ extraction solvent, $\mathrm{MeOH} / 0.5 \mathrm{~mol} \mathrm{~L}^{-1} \mathrm{HCl}(6: 4, \mathrm{v} / \mathrm{v})$ is added and the tube is shaken vigorously, manually for $2 \mathrm{~min}$. The tubes are thereafter transferred to a water bath (at $80^{\circ} \mathrm{C}$ ) and kept there for $15 \mathrm{~min}$. The tubes are allowed to cool down to room temperature and then centrifuged for $15 \mathrm{~min}$ at $4000 \mathrm{rpm}$. From the final extract, $10 \mu \mathrm{L}$ is injected in the UPLC-MS/MS system.

It is very important to mention that throughout the whole procedure and for the autosampler vials, use of glass ware must be avoided and only polypropylene tubes and vials must be used in order to not lose the analytes.

\subsection{Validation experiments}

\subsubsection{Calibration curves, linearity, estimated LOD and LOQ}

The linearity of the analytical curves was established based on injections of the standard solutions at concentrations of $1,2,2.5$, $5,10,50$ and $100 \mathrm{ng} \mathrm{mL}^{-1}$. Each of these solutions was injected seven times $(n=7)$ in the chromatographic system. Average peak responses (areas), relative standard deviations (RSDs) and analytical curve equations were calculated. Also the determination coefficients $\left(\mathrm{r}^{2}\right)$ and linear dynamic ranges were determined for each compound.

Using both the analytical curves equation and the repeatability (RSD) data at the lowest concentration of each individual herbicide studied, the instrument limits of detection $\left(\operatorname{LOD}_{\mathrm{i}}\right)$ and limits of quantification $\left(\mathrm{LOQ}_{\mathrm{i}}\right)$ and also the estimated method LOD and LOQ $\left(\mathrm{LOD}_{\mathrm{m}}\right.$ and $\mathrm{LOQ}_{\mathrm{m}}$, respectively) were calculated.

The $\mathrm{LOD}_{\mathrm{i}}$ was calculated from the RSD\% of the average peak areas of seven replicate injections at the lowest detectable concentration, by the formula: $\operatorname{LOD}_{\mathrm{i}}\left(\mathrm{ng} \mathrm{mL} \mathrm{L}^{-1}\right)=3 \times \mathrm{RSD} \times$ concentration. From these calculated values, a best estimated, rounded $\operatorname{LOD}_{\mathrm{i}}$ value was established. Consequently, this concentration is the lowest injected standard concentration $\left(\mathrm{ng} \mathrm{mL}^{-1}\right)$ that could be detected all seven times, and for which the RSD should not exceed $33 \%$.

The $\mathrm{LOQ}_{\mathrm{i}}$ was calculated via the formula: $\mathrm{LOQ}_{\mathrm{i}}=10 \times$ $\mathrm{RSD} \times$ concentration, which gives $\mathrm{LOQ}_{\mathrm{i}}=3.3 \times \mathrm{LOD}_{\mathrm{i}}$. The real $\mathrm{LOQ}_{\mathrm{m}}$ was based on the accuracy and precision data obtained via the recovery studies and was defined as the lowest validated spike concentration meeting the requirements of a recovery within the range of $70-120 \%$ and an RSD $\leqslant 20 \%$.

\subsubsection{Matrix effect evaluation}

The matrix effect (\%) was calculated in two different ways using data from the analytical solutions in blank cowpea extract and in organic solvent (methanol) via the following formulas:

Matrix effect $(\%)$
$=\left(\frac{\text { peak area std in matrix }- \text { peak area std in solvent }}{\text { peak area std in solvent }}\right) \times 100$

and

Matrix effect $(\%)$

$=\left(\frac{\text { slope analytical curve std in matrix }- \text { slope analytical curve std in solvent }}{\text { slope analytical curve std in solvent }}\right)$ $\times 100$

\subsubsection{Accuracy (trueness and precision)}

The accuracy (trueness and precision) of the method was evaluated through recovery experiments by spiking the mentioned herbicides to blank cowpea at three concentrations $(10,20$ and $\left.50 \mu \mathrm{g} \mathrm{kg}^{-1}\right)$, seven replicates at each level $(\mathrm{n}=7)$. The spiking procedure was performed by adding the standard mixture solution, containing diquat, paraquat and the isotopically labeled internal standards, to the homogenized cowpea slurry before applying the extraction solvent. A blank cowpea, with just the internal standards added, was also extracted and analyzed concurrently.

\subsection{Validation field experiments}

\subsubsection{Field trials}

Field trial validation studies were conducted in three experimental fields of the Brazilian Agricultural Research Corporation Embrapa, in Dourados (Mato Grosso do Sul), Teresina (Piauí) and Sinop (Mato Grosso), in three Brazilian states, from December 2011 to February 2014.

Each field trial consisted of 4 treatments, two sprayings (at stage of 50 and $75 \%$ of dry pods) with those two herbicides (at $300 \mathrm{~g}$ of active ingredient $\mathrm{ha}^{-1}$ and $1.5 \mathrm{~L}$ of commercial product $\mathrm{ha}^{-1}$ ) plus the control treatment (without herbicide). The cultivation type used was the "Nova Era", sown with $0.5 \mathrm{~m}$ spacing between lines and 16 plants/square meter. Crop management followed the good agricultural practices for cowpea. The fertilizers were added according to the soil analysis (Raij, Andrade, Cantarella, \& Quaggio, 2001) and recommendations common for beans (Raij, Cantarella, Quaggio, \& Furlani, 1996). The experimental design was a randomized block with four replications in plots measuring $3.0 \mathrm{~m} \times 7.0 \mathrm{~m}$.

The crop was sprayed considering the pods into two distinct phases, 50 and $75 \%$ of dried pods, whereas most of the seeds had reached physiological maturity. The herbicide spraying was 
performed with a knapsack sprayer pressurized with $\mathrm{CO}_{2}$ and the volume was calibrated in order to spray $150 \mathrm{~L} \mathrm{~h}^{-1}$.

\subsubsection{Gathering samples}

The sampling of the seeds was done on the harvest day of each experiment, in Dourados - MS, Teresina - PI and Sinop - MT, corresponding to 9,7 and 13 days after the last herbicides were sprayed, respectively. The seeds sampling was made at an useful plot area and also on the control plot without herbicide application. Cowpea samples ( $200 \mathrm{~g}$ ) were taken separately from each plot to compose a sample of each treatment. In total, $800 \mathrm{~g}$ of each treatment were fractioned and submitted to extraction of each herbicide studied.

The seed harvest was performed manually after herbicides desiccation. Cowpea seed samples were dried in the shade on aluminum foil and stored in plastic pots coated with the same material, and immediately sent to the laboratory, while keeping them under ambient temperature and humidity conditions during transport to the final destination. In addition to the herbicide residues, the percentage of defoliation, green stems, germination and seed vigor were evaluated (data not shown here).

\section{Results and discussion}

\subsection{Optimization of sample preparation}

It was considered not to use the cowpea powder directly as test portion for analysis, as indicated in the method of the EURL (QuPPe method version $7.1,2013$ ), but to use a sample slurry. With the slurry technique, better homogeneous samples can be obtained, especially for large sized laboratory samples. It also assists in the wetting process of dry samples, in order to make the pesticides better available at the time of extraction (Pizzutti et al., 2012). This is especially important in the case of incurred residues in samples after pesticides application in the field.

During the slurry optimization experiments, it appeared that the most appropriate matrix/water ratio was 1:1.5 (w:w). The visual inspection of the slurry with $1: 1$ ratio demonstrated that this proportion was too dense and slurries with ratios of $1: 3$ and $1: 4$ were too much diluted, which could easily cause segregation.

\subsection{Optimization of extraction solvent composition}

At first, the extraction conditions of the EURL method were tested. At 1:1 ratio methanol/ $\mathrm{HCl} 0.1 \mathrm{~mol} \mathrm{~L}^{-1}$, the recoveries for diquat and paraquat at the three spike concentrations showed too much variation and were completely out of the acceptable recovery range (70-120\%) for paraquat (Table 2 ).

In this study, other proportions of methanol/water and a different concentration of $\mathrm{HCl}$ for extraction optimization of cowpea samples were investigated. In Table 1 , it can be seen that an increase in the percentage of methanol causes a slight decrease of diquat recovery and a major decrease of paraquat recovery values. At the other hand, an increase in $\mathrm{HCl}$ concentration from 0.1 to $0.5 \mathrm{~mol} \mathrm{~L}^{-1}$ caused an increase of the recovery for mainly paraquat. When the methanol proportion is higher than $60 \%$, recoveries for paraquat started to be outside of the acceptable range. A methanol $/ \mathrm{HCl} 0.5 \mathrm{~mol} \mathrm{~L}^{-1}$ composition $60: 40(\mathrm{v} / \mathrm{v})$ showed the optimal recoveries for the three different spike concentrations. No further adjustment of the concentration of $\mathrm{HCl}$ was thus necessary.

It is very striking that, in general, diquat recoveries are good and consistent at all 3 spike concentrations, but paraquat recoveries are many times outside of the $70-120 \%$ range, on both sides. Apparently, even the use of isotopically labeled internal standards could not fully compensate for the changes in absolute recoveries.

\subsection{Effect of extraction temperature and filtration on recovery}

\subsubsection{Temperature}

In the first experiment, the influence of the extraction temperature was investigated by performing the extractions at room temperature and in a water bath at $80^{\circ} \mathrm{C}$, for $15 \mathrm{~min}$. Recoveries were tested at the highest spike concentration $\left(50 \mu \mathrm{g} \mathrm{kg}^{-1}\right)$. The results showed that the recovery seems to be slightly higher at the extraction temperature of $80^{\circ} \mathrm{C}$ for paraquat only (Table 1 ).

In the second experiment, the effect on recoveries (spike concentration of $50 \mu \mathrm{g} \mathrm{kg}^{-1}$ ) of cooling down or not cooling down the extract to room temperature before centrifugation was evaluated. The results are shown in Table 1. Differences in recovery are negligible for paraquat, but diquat recovery improved after cooling down the extract to room temperature.

\subsubsection{Filtration}

The effect on recoveries of omitting or using a filtration step after centrifugation, before injecting the final extract into the UPLC-MS/MS system, was tested for the 3 spike concentrations $\left(10,20\right.$ and $\left.50 \mu \mathrm{g} \mathrm{kg}^{-1}\right)$.

The results in Table 1 show that filtration did not significantly change the recovery value for diquat. Without filtering, the

Table 1

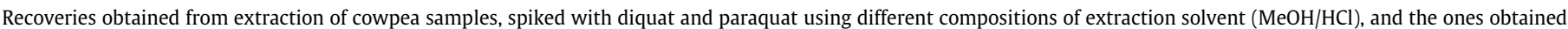
from filtration and temperature study.

\begin{tabular}{|c|c|c|c|c|c|c|c|c|c|c|c|c|c|}
\hline \multirow[t]{3}{*}{ Studied parameter } & \multirow[t]{3}{*}{ Studied condition } & \multicolumn{6}{|c|}{ Diquat } & \multicolumn{6}{|c|}{ Paraquat } \\
\hline & & \multicolumn{2}{|c|}{$10 \mu \mathrm{g} \mathrm{kg}^{-1}$} & \multicolumn{2}{|c|}{$20 \mu \mathrm{g} \mathrm{kg}^{-1}$} & \multicolumn{2}{|c|}{$50 \mu \mathrm{g} \mathrm{kg}^{-1}$} & \multicolumn{2}{|c|}{$10 \mu \mathrm{g} \mathrm{kg}^{-1}$} & \multicolumn{2}{|c|}{$20 \mu \mathrm{g} \mathrm{kg}^{-1}$} & \multicolumn{2}{|c|}{$50 \mu \mathrm{g} \mathrm{kg}^{-1}$} \\
\hline & & $\begin{array}{l}\operatorname{Rec} \\
(\%)\end{array}$ & $\begin{array}{l}\text { RSD } \\
(\%)\end{array}$ & $\begin{array}{l}\operatorname{Rec} \\
(\%)\end{array}$ & $\begin{array}{l}\text { RSD } \\
(\%)\end{array}$ & $\begin{array}{l}\operatorname{Rec} \\
(\%)\end{array}$ & $\begin{array}{l}\text { RSD } \\
(\%)\end{array}$ & $\begin{array}{l}\operatorname{Rec} \\
(\%)\end{array}$ & $\begin{array}{l}\text { RSD } \\
(\%)\end{array}$ & $\begin{array}{l}\operatorname{Rec} \\
(\%)\end{array}$ & $\begin{array}{l}\text { RSD } \\
(\%)\end{array}$ & $\begin{array}{l}\operatorname{Rec} \\
(\%)\end{array}$ & $\begin{array}{l}\text { RSD } \\
(\%)\end{array}$ \\
\hline \multirow[t]{6}{*}{ Extraction solvent } & Methanol/HCl, $0.1 \mathrm{~mol} \mathrm{~L}^{-1}(1: 1)$ & 90 & 2.5 & 86 & 8.5 & 91 & 12.6 & 0 & - & 4 & 2.4 & 7 & 7.9 \\
\hline & Methanol/HCl, $0.5 \mathrm{~mol} \mathrm{~L}^{-1}(1: 1)$ & 104 & 6.9 & 99 & 10.6 & 93 & 6.7 & 268 & 22.9 & 100 & 27.9 & 182 & 12.4 \\
\hline & Methanol/HCl, $0.5 \mathrm{~mol} \mathrm{~L}^{-1}(6: 4)$ & 94 & 2.1 & 94 & 1.7 & 90 & 2.4 & 134 & 21.4 & 103 & 19.7 & 135 & 17.4 \\
\hline & Methanol/HCl, $0.5 \mathrm{~mol} \mathrm{~L}^{-1}(7: 3)$ & 79 & 9.1 & 84 & 4.5 & 89 & 12.2 & 11 & 30.2 & 50 & 15.6 & 36 & 16.8 \\
\hline & Methanol/HCl, $0.5 \mathrm{~mol} \mathrm{~L}^{-1}(8: 2)$ & 83 & 4.7 & 94 & 5.9 & 83 & 14.5 & 23 & 14.4 & 24 & 17.3 & 96 & 26.9 \\
\hline & Methanol/HCl, $0.5 \mathrm{~mol} \mathrm{~L}^{-1}(9: 1)$ & 84 & 2.2 & 90 & 9.8 & 92 & 11.1 & 0 & - & 0 & - & 17 & 14.1 \\
\hline \multirow[t]{2}{*}{ Filtration } & Without filtration & 95 & 5.8 & 94 & 8.7 & 90 & 4.6 & 134 & 15.4 & 103 & 20.1 & 135 & 12.8 \\
\hline & With filtration & 97 & 2.7 & 91 & 4.9 & 94 & 9.9 & 76 & 19.7 & 52 & 17.4 & 53 & 18.1 \\
\hline \multirow[t]{4}{*}{ Temperature } & Room temperature & - & - & - & - & 64 & 10.6 & - & - & - & - & 39 & 15.7 \\
\hline & At $80^{\circ} \mathrm{C}$ & - & - & - & - & 66 & 5.4 & - & - & - & - & 43 & 12.8 \\
\hline & Without extract cooling & - & - & - & - & 60 & 2.9 & - & - & - & - & 41 & 13.0 \\
\hline & With extract cooling & - & - & - & - & 73 & 3.1 & - & - & - & - & 42 & 11.5 \\
\hline
\end{tabular}




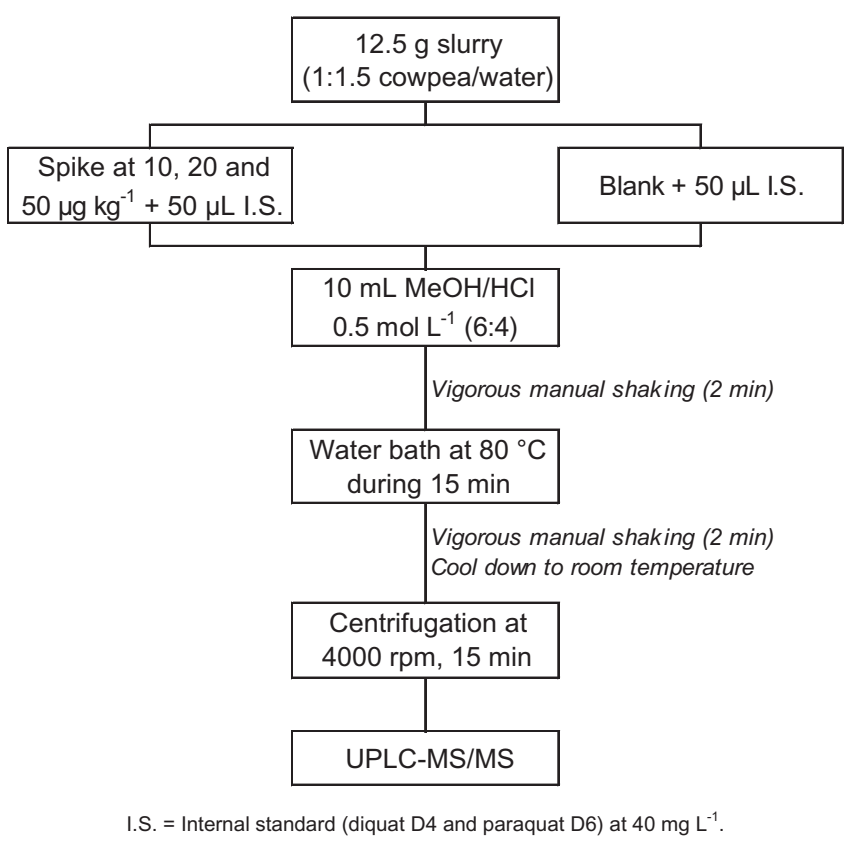

Fig. 1. Validated, optimized procedure for the determination of paraquat and diquat in cowpea, applying UPLC-MS/MS.

recoveries percentages at the three spike concentrations are close to $100 \%$. For paraquat inconsistent results were obtained.

\subsection{Validation}

The final extraction method, after all optimization steps, as shown schematically in Fig. 1, has been validated. The expanded measurement uncertainty ( $\mathrm{U}$ ) for diquat is \pm 0.002 and for paraquat is \pm 0.003 .

\subsubsection{Linearity of analytical curves}

The linearity of the analytical curve of each herbicide was established by plotting the detector response area ratio versus the concentration of the analytical solutions. Both analytes showed

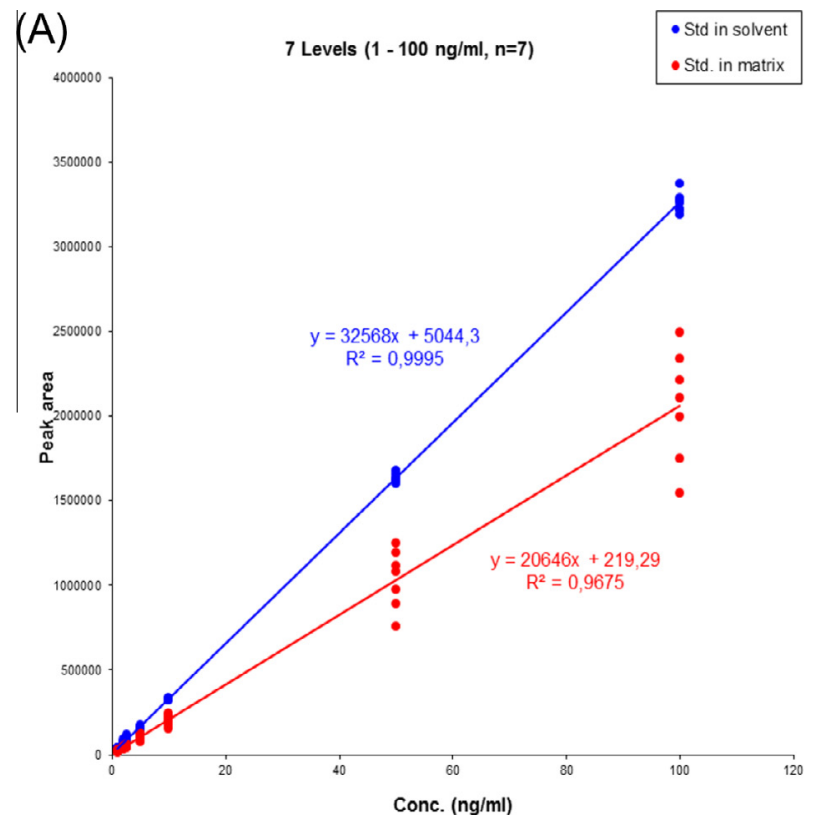

linear behavior in the studied concentration range of $1-100 \mathrm{ng} \mathrm{mL} \mathrm{L}^{-1}$. The determination coefficient $\left(\mathrm{r}^{2}\right)$ was 0.9675 for diquat and 0.9753 for paraquat for analytical solutions prepared in blank matrix extract. For standards solutions prepared in methanol, values of $r^{2}=0.9995$ for diquat and $r^{2}=0.9620$ for paraquat were obtained.

The range of mean $(n=7)$ residuals for the individual pesticide concentrations, from 1 to $100 \mathrm{ng} \mathrm{mL}^{-1}$, was -1.2 to $0.9 \%$ and -16.7 to $3.2 \%$, for diquat and paraquat in solvent, respectively. For the standard solutions prepared in blank matrix extract, the range of mean $(\mathrm{n}=7)$ residuals was $1.2-2.1 \%$ and -26.9 to $2.8 \%$, for diquat and paraquat, respectively. Only the standard solution of paraquat in blank matrix extract at $2 \mathrm{ng} \mathrm{mL}^{-1}$ showed a mean residual of $-26.9 \%$. Otherwise, the range would be from -16.7 to $2.8 \%$.

\subsubsection{Detection and quantification limits ( $L O D$ and $L O Q$ )}

The instrument LOD was estimated as the lowest concentration of herbicide injected that yielded a repeatability RSD of $<33 \%$. This appeared to be the $1 \mathrm{ng} \mathrm{mL} \mathrm{mL}^{-1}$ concentration for both diquat and paraquat. From this, an estimated, rounded instrument and method LOQ of $3 \mathrm{ng} \mathrm{mL}^{-1}$ and $5 \mu \mathrm{g} \mathrm{kg}^{-1}$, respectively, could be calculated. Thus, a lowest spike concentration and target method LOQ of $10 \mu \mathrm{g} \mathrm{kg}^{-1}$ should be realistic.

\subsubsection{Matrix effect for cowpeas}

Matrix components, especially from a difficult matrix as cowpea, can reduce the detector response of the analytes due to ion suppression, that can occur when LC-MS/MS is used. This effect originates in the interface (ion source) when the matrix components co-elute with the target analytes and compete in the ionization process, thereby causing target analyte ion suppression and a reduced analyte signal (Cassiano, Barreiro, Martins, Oliveira, \& Cass, 2009; Kebarle \& Tang, 1993). The sample treatment procedure was designed, aiming at minimizing the potential matrix effects. The matrix effect was evaluated by comparing the slopes of analytical curves obtained from matrix-matched standards and from standards in organic solvent (Fig. 2). Diquat and paraquat both showed a negative matrix effect of $-37 \%$ and $-85 \%$, respectively. Because these matrix effects were very significant, quantification of the pesticides was performed with matrix-matched

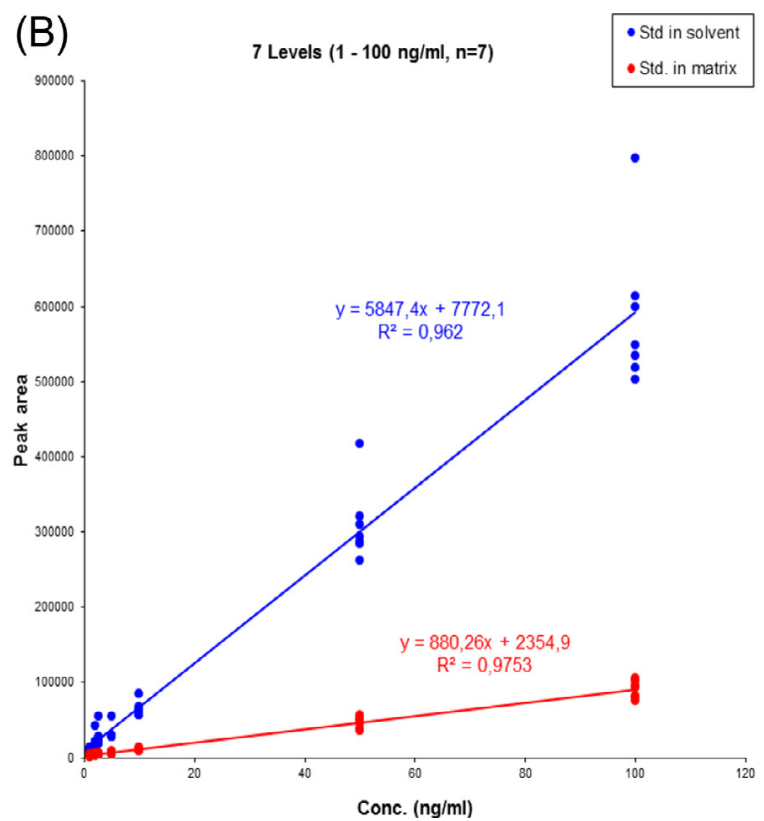

Fig. 2. Analytical curves showing the matrix effect by comparing the slopes of the curves obtained from standards in solvent and those in matrix blank extract; (A) Diquat and (B) Paraquat. 
(A)

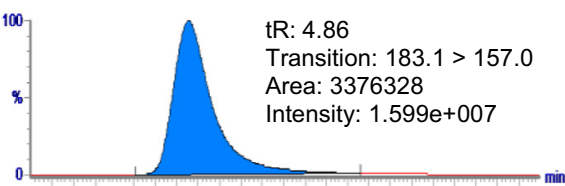

(B)

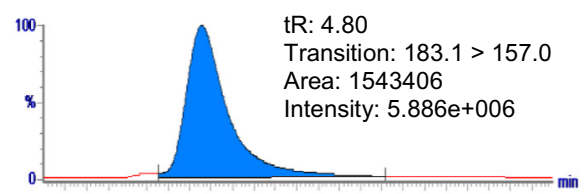

(1)
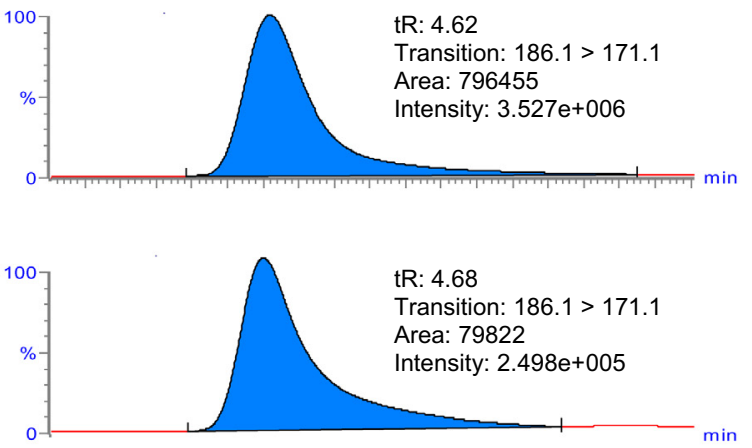

(2)

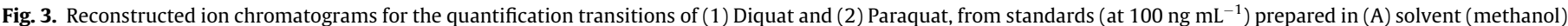
and (B) blank matrix extract. Responses are normalized to $100 \%$; absolute responses given as peak areas and intensities in the figures.

Table 2

Average recoveries and RSDs obtained after extraction of cowpea spiked with paraquat and diquat, at three different levels using the original and the optimized method.

\begin{tabular}{|c|c|c|c|c|c|c|c|}
\hline \multirow[t]{3}{*}{ Method } & \multirow[t]{3}{*}{ Pesticide } & \multicolumn{6}{|c|}{ Spike level $\left(\mu \mathrm{g} \mathrm{kg}^{-1}\right)$} \\
\hline & & \multicolumn{2}{|c|}{10} & \multicolumn{2}{|c|}{20} & \multicolumn{2}{|c|}{50} \\
\hline & & $\operatorname{Rec}(\%)$ & RSD (\%) & $\operatorname{Rec}(\%)$ & RSD (\%) & $\operatorname{Rec}(\%)$ & RSD (\%) \\
\hline \multirow[t]{2}{*}{ Optimized method } & Diquat & 77 & 1.9 & 78 & 1.1 & 85 & 1.4 \\
\hline & Paraquat & 103 & 25.4 & 82 & 14.4 & 68 & 20.2 \\
\hline \multirow[t]{2}{*}{ EURL-method } & Diquat & 90 & 5.9 & 86 & 10.6 & 91 & 14.8 \\
\hline & Paraquat & 0 & 2.0 & 4 & 20.7 & 7 & 22.8 \\
\hline
\end{tabular}

calibration, besides the use of isotopically labeled internal standards. Fig. 3 shows the reconstructed ion chromatograms of the quantification transitions for diquat and paraquat, showing the reduction of signal intensity when these compounds were analyzed in matrix extract compared to standards in solvent (methanol).

\subsubsection{Accuracy (trueness and precision) and selectivity}

The optimization of the extraction method for determination of paraquat and diquat in cowpea finally resulted in satisfactory recovery data, as can be seen in Table 2 . The average recoveries for diquat ranged from $77 \%$ to $85 \%$ for the 3 spike concentrations $\left(10,20\right.$ and $50 \mu \mathrm{g} \mathrm{kg}^{-1}$ ), with a very good precision (RSDs $<2 \%$ ). Paraquat proved to be a very difficult pesticide to analyze in the also difficult cowpea matrix. At the 3 spike levels studied significantly different average recoveries were obtained of 103,82 and $68 \%$, respectively. Also the RSDs were much higher than for diquat, although still $\leqslant 20 \%$, except for the lowest spike concentration. Thus the data are in agreement with the quantitative method performance criteria of document No. SANCO/12571/2013 (SANCO, 2013), with an average recovery of $70-120 \%$ and a withinlaboratory repeatability $\mathrm{RSD}_{\mathrm{r}} \leqslant 20 \%$. Therefore, the developed method can be considered sufficiently accurate and precise, and fit for purpose.

The validated method LOQs are $10 \mu \mathrm{g} \mathrm{kg}^{-1}$ for diquat and $20 \mu \mathrm{g} \mathrm{kg}^{-1}$ for paraquat. These values are below the maximum residue limits (MRLs) according to EU ( 0.05 and $0.02 \mathrm{mg} \mathrm{kg}^{-1}$ for diquat and paraquat, respectively) and ANVISA (0.5 and $0.05 \mathrm{mg} \mathrm{kg}^{-1}$ for diquat and paraquat, respectively).

\subsubsection{Method comparison}

In order to show the improvement of the developed and optimized method relative to the EURL method, a comparison of both was executed as recoveries at the three different spike concentrations. Table 2 demonstrates that the optimized method has similar recoveries for diquat, but is much more efficient for paraquat at all three spike concentrations for the cowpea matrix studied.

\subsection{Determination of diquat and paraquat in cowpea samples from a field study (EMBRAPA)}

The optimized method was applied to analyze cowpea samples from a field study. The samples originated from a study performed by EMBRAPA, evaluating the effectiveness of different desiccant herbicides, as to the active ingredient, formulation and implementation period in the cultivation of cowpea. The optimized and validated procedure was applied to 15 samples, which were analyzed in triplicate by UPLC-MS/MS. The results for the cowpea samples are presented in Table 3.

Results for samples from Piauí state (Teresina city) showed that for both diquat and paraquat the residue concentration is $\sim 10$ to 15 times higher for the samples from application of the herbicides at the stage of $50 \%$ dry pods compared to the samples from application at the stage of $75 \%$ dry pods.

For the samples from Mato Grosso do Sul state (Dourados city) with sample numbers $6-10$, no residues could be detected above the method LOQ for both diquat and paraquat. Samples 12-15 from Mato Grosso state (Sinop city) showed detectable residues (>LOQ) in the range of $0.02-0.06$ and $0.01-0.02 \mathrm{mg} \mathrm{kg}^{-1}$ for paraquat and diquat, respectively. The concentrations for the samples from application of the herbicides at the stage of 50\% dry pods were slightly higher compared to the samples from application at the stage of $75 \%$ dry pods. The average residues for paraquat taken at the stage of $50 \%$ dry pods were slightly exceeding the Brazilian MRL $\left(0.05 \mathrm{mg} \mathrm{kg}^{-1}\right)$. In none of the samples analyzed, the Brazilian MRL for diquat $\left(0.5 \mathrm{mg} \mathrm{kg}^{-1}\right)$ was exceeded.

Differences in residue concentrations between the states are correlated to weather conditions during the cowpea growing. Periods of water stress for plants or high temperatures can accelerate the process of drying the pods or decrease absorption rates of 
Table 3

Concentrations of paraquat and diquat detected in cowpea samples from the EMBRAPA field study.

\begin{tabular}{|c|c|c|c|c|c|}
\hline Sample number & Origin & Field treatment & $\begin{array}{l}\text { Replicate } \\
\text { number }\end{array}$ & $\begin{array}{l}\text { Diquat } \\
\left(\mathrm{mg} \mathrm{kg}^{-1}\right)\end{array}$ & $\begin{array}{l}\text { Paraquat } \\
\left(\mathrm{mg} \mathrm{kg}^{-1}\right)\end{array}$ \\
\hline 1 & Piauí state (Teresina City) & Blank sample & 1 & nd & nd \\
\hline \multirow[t]{3}{*}{2} & & Paraquat applied at stage of $50 \%$ dry pods & 1 & nd & 0.267 \\
\hline & & & 2 & nd & 0.261 \\
\hline & & & 3 & nd & 0.240 \\
\hline \multirow[t]{3}{*}{3} & & Paraquat applied at stage of $75 \%$ dry pods & 1 & nd & 0.020 \\
\hline & & & 2 & nd & $<\mathrm{LOQ}$ \\
\hline & & & 3 & nd & $<$ LOQ \\
\hline \multirow[t]{3}{*}{4} & & Diquat applied at stage of $50 \%$ dry pods & 1 & 0.313 & nd \\
\hline & & & 2 & 0.321 & nd \\
\hline & & & 3 & 0.318 & nd \\
\hline \multirow[t]{3}{*}{5} & & Diquat applied at stage of $75 \%$ dry pods & 1 & 0.022 & nd \\
\hline & & & 2 & 0.021 & nd \\
\hline & & & 3 & 0.020 & nd \\
\hline 6 & Mato Grosso do Sul state (Dourados City) & Blank sample & 1 & nd & nd \\
\hline \multirow[t]{3}{*}{7} & & Paraquat applied at stage of $50 \%$ dry pods & 1 & nd & $<$ LOQ \\
\hline & & & 2 & nd & $<$ LOQ \\
\hline & & & 3 & nd & $<\mathrm{LOQ}$ \\
\hline \multirow[t]{3}{*}{8} & & Paraquat applied at stage of $75 \%$ dry pods & 1 & nd & $<$ LOQ \\
\hline & & & 2 & nd & $<$ LOQ \\
\hline & & & 3 & nd & $<\mathrm{LOQ}$ \\
\hline \multirow[t]{3}{*}{9} & & Diquat applied at stage of $50 \%$ dry pods & 1 & $<$ LOQ & nd \\
\hline & & & 2 & $<$ LOQ & nd \\
\hline & & & 3 & $<$ LOQ & nd \\
\hline \multirow[t]{3}{*}{10} & & Diquat applied at stage of $75 \%$ dry pods & 1 & $<$ LOQ & nd \\
\hline & & & 2 & $<$ LOQ & nd \\
\hline & & & 3 & $<\mathrm{LOQ}$ & nd \\
\hline 11 & Mato Grosso state (Sinop City) & Blank sample & 1 & nd & nd \\
\hline \multirow[t]{3}{*}{12} & & Paraquat applied at stage of $50 \%$ dry pods & 1 & nd & 0.055 \\
\hline & & & 2 & nd & 0.050 \\
\hline & & & 3 & nd & 0.049 \\
\hline \multirow[t]{3}{*}{13} & & Paraquat applied at stage of $75 \%$ dry pods & 1 & nd & 0.023 \\
\hline & & & 2 & nd & 0.025 \\
\hline & & & 3 & nd & 0.022 \\
\hline \multirow[t]{3}{*}{14} & & Diquat applied at stage of $50 \%$ dry pods & 1 & 0.017 & nd \\
\hline & & & 2 & 0.018 & nd \\
\hline & & & 3 & 0.017 & nd \\
\hline \multirow[t]{3}{*}{15} & & Diquat applied at stage of $75 \%$ dry pods & 1 & 0.014 & nd \\
\hline & & & 2 & 0.014 & nd \\
\hline & & & 3 & 0.013 & nd \\
\hline
\end{tabular}

nd: not detected.

$\mathrm{LOQ}_{\mathrm{m}}$ for Diquat/Paraquat: $0.01 / 0.02 \mathrm{mg} \mathrm{kg}^{-1}$.

herbicides, resulting in residue accumulation. In general, considering the results of samples from different regions, a lower residue level effect of both herbicides can be observed, when desiccant herbicide applications were performed in a more advanced stage of cowpea growth. Samples 3, 5, 13 and 15, corresponding to the treatments at the stage of $75 \%$ of dry pods illustrate this. The effect can be explained by the lower absorption of herbicides in the dry pods and lower translocation to the grains.

From the field study, it can be concluded that the optimum stage of applying the herbicides paraquat or diquat and harvesting the cowpeas is when the pods have a water content of $50 \%$ or less, which results in residue concentrations below the MRL. Residue monitoring before and/or at harvest time is thus highly recommended. The method developed and validated in our study has proven to be fit for purpose of residue monitoring in cowpeas.

\section{Conclusions}

The optimized procedure for diquat and paraquat extraction from cowpea samples involves extraction with methanol $/ \mathrm{HCl}$ $0.5 \mathrm{M}(6: 4)$ at $80^{\circ} \mathrm{C}$ for $15 \mathrm{~min}$. The analyses were performed by UPLC-MS/MS using isotopically labeled analogues of the target pesticides as internal standards, in order to effectively eliminate errors caused due to losses during sample preparation or to compensate for matrix effect in UPLC-MS/MS. The validation studies, using cowpea spiked with diquat and paraquat at three concentrations, revealed that the optimized method is robust and suitable for cost effective routine analysis of these herbicides, achieving good recoveries for all spike levels tested. Good recoveries (within the acceptable range of $70-120 \%$ ), good precision (with RSDs $<20 \%$ ) were achieved during method validation. The low method LOQs of 0.01 and $0.02 \mathrm{mg} \mathrm{kg}^{-1}$ for diquat and paraquat, respectively, illustrate the good sensitivity for this difficult matrix of cowpeas. The method was successfully applied in a survey to analyze samples from a field study performed by EMBRAPA. Positive residue findings were observed in cowpea samples, emphasizing the need for residue monitoring at the relevant stages of growing.

\section{Acknowledgements}

To MAPA, MCTI, FINEP, CNPq, CAPES, UFSM and NVWA.

\section{References}

Almeida, R. M., \& Yonamine, M. (2007). Gas chromatographic-mass spectrometric Method for the determination of the Herbicides paraquat and diquat in plasma and urine samples. Journal of Chromatography B, 853, 260-264.

Anastassiades, M., Kolberg, D. I., Mack, D., Sigalova, I., Roux, D., \& Fügel, D. (2013). EU Reference Laboratory for Residues of Pesticides, Quick Method for the Analysis of Residues of numerous Highly Polar Pesticides in Foods of Plant Origin involving 
Simultaneous Extraction with Methanol and LC-MS/MS Determination (QuPPeMethod). Version 7.1. Available at http://www.eurl-pesticides.eu.

ANVISA (Brazilian Sanitary Surveillance Agency). (2015). Monografias de Agrotóxicos Available at: <http://portal.anvisa.gov.br/wps/content/Anvisa+Portal/Anvisa/ Inicio/Agrotoxicos+e+Toxicologia/Assuntos+de+Interesse/Monografias+de +Agrotoxicos/Monografias> Accessed 15.04.15.

Cassiano, N. M., Barreiro, J. C., Martins, L. R. R., Oliveira, R. V., \& Cass, Q. B. (2009) Chromatographic methods validation for analysis of small molecules in biological matrices. Química Nova, 32, 1021-1030.

Castro, R., Moyano, E., \& Galceran, M. T. (2001). Ion-trap versus quadrupole for analysis of quaternary ammonium Herbicides by LC-MS. Chromatographia, 53, 273-278.

Farahi, A., Achak, M., Gaini, L. El., Mhammedi, EI., \& Bakasse, M. (2014). Silver particles-modified carbon paste electrodes for differential pulse voltammetric determination of paraquat in ambient water samples. Journal of the Association of Arab Universities for Basic and Applied Sciences. http://dx.doi.org/10.1016/ j.jaubas.2014.06.011. In Press.

Gao, L., Liu, J., Wang, C., Liu, G., Niu, X., Shu, C., \& Zhu, J. (2014). Fast determination of paraquat in plasma and urine samples by solid-phase microextraction and gas chromatography-mass spectrometry. Journal of Chromatography B, 944, $136-140$.

Garcia-Febrero, R., Salvador, J. P., Sanchez-Baeza, F., \& Marco, M. P. (2014). Rapid Method based on immunoassay for determination of paraquat residues in wheat, barley and potato. Food Control, 41, 193-201.

Grey, L., Nguyen, B., \& Yang, P. (2002). Liquid chromatography-electrospray ionization isotope dilution mass spectrometry analysis of paraquat and diquat using conventional and multilayer solid-phase extraction cartridges. Journal of Chromatography A, 958, 25-33.

Guidance document on analytical quality control and validation procedures for pesticide residues analysis in food and feed. (2013). SANCO. Document No. SANCO/12571/2013.

Hao, C., Zhao, X., Morse, D., Yang, P., Taguchi, V., \& Morra, F. (2013). Optimized liquid chromatography tandem mass spectrometry approach for the determination of diquat and paraquat herbicides. Journal of Chromatography A, 1304, 169-176.

Harmoudi, H. El., Achak, M., Farahi, A., Lahrich, S., Gaini, L. El., Abdennouri, M., Bouzidi, A., et al. (2013). Sensitive determination of paraquat by square wave anodic stripping voltammetry with chitin modified carbon paste electrode. Talanta, 115, 172-177.

Harmoudi, H. El., Achak, M., Lahrich, S., Farahi, A., Gaini, L. El., Bakasse, M., \& Mhammedi, M. A. El. (2012). Square wave voltammetric determination of diquat using natural phosphate modified platinum electrode. Arabian Journal of Chemistry. http://dx.doi.org/10.1016/j.arabjc.2012.11.007. In Press.

Kebarle, P., \& Tang, L. (1993). From ions in solution to ions in the gas phase - the mechanism of electrospray mass spectrometry. Analytical Chemistry, 65, 972-986.

Kolberg, D. I. S., Mack, D., Anastassiades, M., Hetmanski, M. T., Fussell, R. L., Meijer, T., \& Mol, H. G. J. (2012). Development and independent laboratory validation of a simple method for the determination of paraquat and diquat in potato, cereals and pulses. Analytical and Bioanalytical Chemistry, 404, 2465-2474.

Maya, F., Estela, J. M., \& Cerdà, V. (2011). Improved spectrophotometric determination of paraquat in drinking Waters exploiting a multisyringe liquid core waveguide system. Talanta, 85, 588-595.

Paraquat information center. (2015). Available at: http://paraquat.com/portugues/ seguran\%C3\%A7a/regulamenta\%C3\%A7\%C3\%A3o Accessed 15.04.15.

Pizzutti, I. R., De Kok, A., Cardoso, C. D., Reichert, B., De Kroon, M. W., \& Wind, W. (2012). A multi-residue method for pesticides analysis in green coffee beans using gas chromatography-negative chemical ionization mass spectrometry in selective ion monitoring mode. Journal of Chromatography A, 1251, 16-26.

Raij, B. van, Andrade, J. C. Cantarella, H., \& Quaggio, J. A. (2001). Análise química para avaliação da fertilidade do solo (p. 285p). Campinas: Instituto Agronômico.

Raij, B. van, Cantarella, H., Quaggio, J. A., \& Furlani, A. M. C. (1996). Recomendações de adubação e calagem para o Estado de São Paulo (2nd ed.)Campinas: Instituto Agronômico (Boletim Técnico, 100).

Ruan, X., Qiu, J., Wu, C., Huang, T., Meng, R., \& Lai, Y. (2014). Magnetic single-walled carbon nanotubes-dispersive solid-phase extraction method combined with liquid chromatography-tandem mass spectrometry for the determination of paraquat in urine. Journal of Chromatography B, 965, 85-90.

Shawish, H. M. A., Ghalwa, N. A., Hamada, M., \& Basheer, A. (2012). Modified carbon paste electrode for potentiometric determination of diquat dibromide pesticide in water and urine samples. Materials Science and Engineering C, 32, 140-145.

The Pesticide Manual (2012). British Crop Protection Council (16th ed.). Alton, Hampshire, UK.

Tyszczuk-Rotko, K., Beczkowska, I., \& Nosal-Wiercinska, A. (2014). Simple, selective and sensitive voltammetric method for the determination af herbicide (paraquat) using bare boron-doped diamond electrode. Diamond \& Related Materials, 50, 86-90.

Yao, F., Liu, H., Wang, G., Du, L., Yin, X., \& Fu, Y. (2013). Determination of paraquat in water samples using a sensitive fluorescent probe titration method. Journal of Environmental Sciences, 25, 1245-1251. 